DOCTRINA

\title{
Estándares técnico-jurídicos de gestión para servicios digitales de información legislativa
}

\author{
Technical-legal management standards \\ for digital legislative information services
}

\author{
Patricia Reyes Olmedo \\ Universidad de Valparaíso, Chile
}

\begin{abstract}
RESUMEN Constituye un desafío en un Estado de derecho dar acceso y conocimiento a los contenidos de los textos legales bajo modernos estándares de gestión de información que permitan un eficiente y eficaz almacenamiento, procesamiento, búsqueda, recuperación y comunicación de las normas. En el artículo se revisan los estándares reconocidos internacionalmente para los servicios digitales de información legislativa. La autora propone que la web semántica legislativa, basada en las tecnologías de documento estructurado (XML), metadatos (RDF) y ontologías (OWL) aparece como modelo óptimo de plataforma para la representación, organización y distribución de contenidos jurídicos, y constituye una respuesta eficaz a los requerimientos originados por el fenómeno de la contaminación legislativa y a la demanda de mejor acceso a la legislación.
\end{abstract}

PALABRAS CLAVE Servicios de información legislativa, web semántica legislativa, datos abiertos, información oficial, gestión de información legal.

ABSTRACT A challenge of rule of Law is to provide access to the contents of legal texts under modern information management standards for its efficient and effective storage, processing, search, retrieval and communication. The article reviews the international standards for digital legislative information services. The author proposes that the legislative semantic web, based on the technologies of structured document (XML), metadata (RDF) and ontologies (OWL) appears as the optimal platform model for the representation, organization and distribution of these legal contents, and is an effective response to the requirements caused by the phenomenon of legislative contamination and the demand for better and easier access to legislation.

KEYWORDS Legislative information services, legislative semantic web, open data, official information, legal information management. 


\section{Servicios de información legislativa}

El contexto de la sociedad red (Castell, 2001) exige redefinir el escenario en que se prestan los servicios de información legislativa.

En efecto, esta información, cada vez más abundante y extensa, y su demanda en línea con carácter de inmediatez, requiere una organización y procesamiento que permita su búsqueda y recuperación, de manera no sólo eficiente y eficaz, sino que cumpla ciertos requisitos que faciliten la realización de los principios de publicidad, seguridad jurídica e inexcusabilidad del conocimiento de la ley.

No obstante lo anterior, se debe reconocer que tradicionalmente las funciones de almacenar, procesar e incluso difundir información legislativa han sido vistas como una actividad propia de otras disciplinas, con componentes de carácter técnico y sin interés para los investigadores del derecho, pese a que ella normalmente es una herramienta fundamental en el trabajo diario del operador jurídico, un servicio de apoyo indispensable para el proceso de formación de la ley y para la propia elaboración las decisiones jurisdiccionales.

Por otra parte, y siguiendo a Saarenpää (2012), se debe entender que la información legal no es principalmente para los abogados, aunque la teoría jurídica podría sugerir lo contrario. La legislación es creada para todos los actores de la sociedad. En términos de derechos individuales, se trata de información que rige la conducta en sociedad y, por tanto, es más importante que la mayoría de la información que se recibe.

Así visto, constituye un desafío en todo Estado de derecho dar acceso y conocimiento a los contenidos legislativos, lo cual implica implementar los más modernos y eficaces métodos y estándares de gestión de información legislativa para lograr un adecuado almacenamiento, procesamiento, búsqueda, recuperación y comunicación de las normas, pues como también se observa en otras áreas del conocimiento, el contenido ha pasado a ser el principal motor de la demanda de información legal.

Los editores legales, incluido el Estado, deben garantizar el acceso universal al contenido oficial de las normas legales bajo estándares internacionales de gestión informacional, es decir, la difusión digital de la ley no sólo debe garantizar la autenticidad, validez e integridad del texto oficial, sino la calidad de sus procesos, la seguridad de la información almacenada, su preservación en el tiempo y, en forma indispensable, su acceso universal, pues se trata de información pública que debe estar abierta para su acceso, uso y reutilización, de manera gratuita, en cualquier lugar y a cualquier hora.

Bajo este prisma, se analizan a continuación, en primer lugar, los servicios digitales de información legislativa a la luz de los estándares generales básicos exigidos en un modelo de servicio de acceso universal, para luego revisar los estándares específicos para el procesamiento y servicio de esta información bajo el modelo moderno de 
web semántica legislativa (García Marco, 2009), que en concepto de los especialistas constituye el mayor desafío en la construcción de estos servicios actualmente.

Dentro de los estándares generales se considera su carácter digital, apertura, gratuidad, oficialidad o autenticidad, disponibilidad, licenciamiento libre, confidencialidad restringida, preservación, seguridad y la calidad de los procesos de esta información.

En el análisis del modelo se consideran las tecnologías y herramientas que distinguen la web semántica, tales como el lenguaje de marcado, los metadatos y las ontologías, pero especialmente, siguiendo a García Marco (2009) y Palmirani y Vitali (2012), se analizan los usos y ventajas de su utilización para el almacenamiento, procesamiento, recuperación y comunicación de la información legislativa, que refieren las mayores bondades para el logro del objetivo de garantizar el principio de seguridad y certeza jurídica.

\section{Estándares generales para los servicios de información legislativa}

Los retos y desafíos que enfrentan hoy los servicios informativos, junto a las exigencias sociales de mayor transparencia de la información legislativa, permiten establecer una serie de estándares básicos para la implementación de un moderno servicio de información legal, elementos esenciales a nuestro juicio de una gestión informacional que asegure acceso y mayor conocimiento de esta información.

\section{Soporte digital}

En materia de publicidad de la ley, hoy en día el medio impreso no resulta ser una herramienta eficaz, pues vivimos en una sociedad caracterizada por sus redes y sistemas de información. En este orden de ideas, la publicación electrónica de la ley constituye un estándar requerido para dar publicidad a las normas jurídicas y cumplir con las aspiraciones de mayor eficacia de su comunicación.

En efecto, el advenimiento de las tecnologías de información y comunicaciones (TIC) está cambiando radicalmente el modelo y los costos del mismo para el usuario final de servicios de información legal, lo que está terminando con los monopolios que las grandes editoriales jurídicas, tales como Lexis Nexis y Swisslex, detentaban en el mundo. Las plataformas en línea de publicación de las normas han ido ganando progresivamente espacios desde hace algunos años e incluso han sustituido completamente la publicación impresa oficial.

Incluso la doctrina, que se mostró reticente a este cambio, ${ }^{1}$ ha devenido en consi-

1. De acuerdo con ésta, «es preciso admitir que la escritura es un vehículo o medio de fijación o de plasmación que cumple una función de certidumbre muy importante. Hoy por hoy no parece fácil encontrar cauces de recepción y de almacenamiento de la información jurídica que puedan superar al 
derar la publicación electrónica más eficaz para responder al principio de publicidad de la ley. Así, por ejemplo, se ha señalado que «podría concluirse prima facie que la publicación online suministra el mismo grado de cognoscibilidad, o incluso superior, que la proporcionada por la publicación realizada en un periódico oficial» (Torres Lana, 2005: 30). Para el mismo autor no parece haber duda de que la publicación en línea puede cumplir la finalidad de hacer posible el conocimiento de las normas a un mayor número de personas.

No obstante que esta discusión doctrinal parece zanjada, se debe decir que la preocupación por el diseño, desarrollo e implementación de servicios en línea surge en Europa mucho más tempranamente que en América Latina, y ya en el año 1983 el Consejo Europeo, inspirado en el creciente mercado de bancos de datos jurídicos, emite la Recomendación REC (1983) 33F relativa a la Protección de Usuarios de Servicios de Informática Jurídica, ${ }^{2}$ por la que propone la adopción de medios apropiados para la protección de los usuarios de estos servicios de información jurídica, definidos como «aquel servicio (institución o conjunto de instituciones diferentes, sea cual fuere su forma de organización) que a través de medios automatizados proporciona información sobre documentos jurídicos de una o varias de las siguientes categorías: la legislación, la jurisprudencia y la doctrina». Sugiere además a los Estados miembros «facilitar el acceso de los servicios de información jurídica a los textos jurídicos básicos (legislación, jurisprudencia, textos administrativos)».

Posteriormente, en lo que se entiende como un planteamiento basado en una visión sociopolítica y no mercantil como la anterior, el año 2001 el mismo Consejo Europeo, ahora a través de Recomendación REC (2001) 3F, referida a los «Servicios otorgados a los ciudadanos por los tribunales y otras instituciones jurídicas utilizando las TIC»,3 sugiere a los Estados «la difusión electrónica de las leyes y la creación de servicios gratuitos que faciliten a los ciudadanos el acceso a la legislación vigente, sin perjuicio de que existan también servicios complementarios desarrollados por el sector privado».

Se colige de esta recomendación que es el Estado el que debe garantizar que el ciudadano conozca con certeza las normas aplicables a través de plataformas electrónicas oficiales públicas y gratuitas, las que incluso han venido a reemplazar la publicación oficial impresa en algunos países, como por ejemplo se observa en los portales

derecho escrito. Aun cuando se realizan ensayos con ordenadores electrónicos, no parece que se esté todavía en condiciones de jubilar a la letra escrita y la letra impresa» (Díez Picazo, 1999: 101)

2. Recomendación REC (83) 3F del Comité de Ministros de los Estados Miembros relativa a la Protección de Usuarios de Servicios de Informática Jurídica. Disponible en http://bit.ly/2ynnLqZ.

3. Recomendación REC (2001) 33 F del Comité de Ministros de los Estados Miembros sobre los Servicios otorgados por los tribunales de justicia y otras instituciones jurídicas a los ciudadanos utilizando las nuevas tecnologías. Disponible en $h \mathrm{ttp}: / /$ bit.ly/2ynwcmo. 
Bundeskanzleramt de Austria, ${ }^{4}$ Post-Och Inrikes Tidningar de Suecia ${ }^{5}$ y EUR-LEX de la Comunidad Económica Europea. ${ }^{6}$

\section{Apertura de la información}

Las altas exigencias actuales de transparencia han puesto de relieve la necesidad de acceder a información. Sin embargo, la práctica ha denotado que no basta con que la información esté disponible, sino que debe cumplir con ciertos requisitos para satisfacer las expectativas informacionales, no solo de los expertos, sino también de los ciudadanos.

Bajo esta exigencia cada vez más amplia, hace ya algunos años surge un movimiento que intenta crear conciencia e incentivar el conocimiento abierto, la apertura de datos o los datos abiertos (open data), compeliendo a los responsables de la información a implementar un acceso a la misma que cumpla con ciertos estándares que permitan que los datos puedan además ser usados, reutilizados y redistribuidos por cualquiera que acceda a ellos.

Para que esto último ocurra, este conocimiento debe satisfacer los siguientes requisitos cuando se distribuye:

- Licencia abierta: Las condiciones legales bajo las cuales está disponible la información deben permitir su uso, redistribución, modificación, compilación o propagación con cualquier propósito.

- Acceso: Significa que la información debe estar disponible como un todo, con sólo un coste razonable de reproducción, y preferiblemente descargable de manera gratuita a través de internet.

- Formato abierto: Debe proporcionarse de manera que no haya obstáculos tecnológicos innecesarios para el uso de la información. Concretamente, los datos deben poder ser leídos automáticamente y estar disponibles en un formato con especificaciones disponibles en forma pública, libre y gratuita.

Bajo estos parámetros, la cultura de la apertura se ha reafirmado posteriormente, pues la experiencia empírica ha demostrado que la mejor forma de utilizar tus datos se les ocurrirá a los otros. Así lo ha expresado por ejemplo el grupo de trabajo Networking and Information Technology Research and Development (NITRD) de la Oficina de Política Científica y Tecnológica de los Estados Unidos de Norteamérica, al describir la importancia de los datos abiertos y compartidos especialmente en materia de ciencia y tecnología. Para el grupo de trabajo,

4. Bundeskanzleramt, Gaceta Oficial de Austria, disponible en http://bit.ly/2jXUIWI.

5. Post-Och Inrikes Tidningar. Gaceta Oficial Sueca. Disponible en http://bit.ly/2ynMooX.

6. EUR-LEX, edición electrónica auténtica del Diario Oficial de la Unión Europea. Disponible en http://bit.ly/2ynDOVO. 
el poder de la información digital es limitado solamente por el poder de la mente humana. Los datos no son consumidos por las ideas y las innovaciones, ya que esa chispa da origen o son más bien un combustible sin fin para la creatividad. Incluso un pequeño fragmento de información, si se encuentra, puede conducir a un gran salto de la creatividad. El poder de un conjunto de datos puede ser amplificado por el ingenio a través de aplicaciones inimaginables por los autores y distar absolutamente del campo u objetivo original (NITRD, 2009: 1, la traducción es nuestra).

En consonancia y como derivación de este concepto de datos abiertos, aparece el de datos gubernamentales abiertos (open gov data), que entiende que tratándose de información pública, ésta debe ser abierta, ya que es la que cumple con las mejores de condiciones para su uso, reutilización y redistribución, pues los resultados de estos procesos generan alto valor público, entendido por tal lo que Moore (1998) define como la experiencia que un ciudadano tiene con una institución pública o sus representantes que considera valiosa en el sentido de aprender, fortalecer su identidad, ahorrar tiempo o dinero y finalmente sentirse gratificado.

Se debe poner de manifiesto que detrás de estas aproximaciones también hay una filosofía económica, recogida en el estudio de Newbery, Bently y Pollok (2008), que entiende que la entrega gratuita de datos públicos es la forma más eficiente para incrementar el bienestar social si se la compara con otros modelos de distribución de información. De hecho, en el ámbito europeo desde hace mucho tiempo se ha dado prioridad a estos argumentos de orden económico, al señalar que el fácil acceso a esta información por parte del sector empresarial constituye un motor de la economía en la Unión Europea. Así, por ejemplo, en el Libro verde de la Comisión Europea sobre la información del sector público en la sociedad de la información (Comisión Europea, 1998) dedica un apartado a detallar las oportunidades que esta información brindaría al crecimiento económico y al empleo.

Se puede sostener entonces que las iniciativas de datos gubernamentales abiertos son motores de crecimiento económico, cuestión que se encuentra sustentada en alguna evidencia empírica también, como la recogida por Fornefeld y otros (2009) en su estudio sobre la reutilización de la información del sector público.

Establecido lo anterior, y como la información legislativa constituye información pública, a continuación se revisa el concepto y los principios que configuran esta apertura de la información pública o datos gubernamentales abiertos.

\section{Concepto}

Para los fundadores del movimiento de datos abiertos, que mantienen el sitio web Open Definition, ${ }^{7}$ el «conocimiento es abierto si cualquiera es libre para acceder a él,

7. Disponible en http://opendefinition.org/. 
usarlo, modificarlo y compartirlo bajo condiciones que, como mucho, preserven su autoría y su apertura».

De otra parte, los datos gubernamentales abiertos son definidos por sus propulsores como información del sector público que se comparte en forma digital, a través de internet, de una manera que promueva su análisis y reutilización.

El concepto de datos gubernamentales abiertos y su filosofía se expande con fuerza en el mundo entero a partir del año 2007 , fecha en que tuvo lugar la reunión de Sebastopol, ${ }^{8}$ en que se desarrollaron los primeros «8 Principles of Open Government Data» (Los Ocho Principios de la Apertura de Datos Gubernamentales, traducción libre de la autora). La filosofía se sostiene sobre el fundamento que la información pública gubernamental constituye un recurso o insumo informacional extremadamente valioso.

\section{Principios de la apertura de la información pública}

De acuerdo con lo establecido en la reunión de Sebastopol, los principios que informan la apertura de datos gubernamentales, y que actualmente se exponen en el portal Open Government Data, ${ }^{9}$ son los siguientes:

- Completitud: Debe abrirse toda la información elaborada por los órganos públicos o con recursos públicos y que no está sujeta a reserva o secreto bajo causal legal.

- Originalidad o fuente primaria (raw data): Los datos deben corresponder a los emanados de su fuente de origen y deben disponerse con el mayor nivel de granulidad posible, sin formatos agregados o modificados.

- Oportunidad: La información debe ponerse a disposición de todos lo más pronto posible, a fin de conservar su valor.

- Disponibilidad: Los datos deben estar disponibles en todo momento, a todo tipo de usuarios y para todos los propósitos.

- Procesabilidad: Los datos deben contener estructuras razonables que permitan ser procesados automáticamente.

- Sin discriminación: Los datos deben estar disponibles a cualquiera sin necesidad de registro.

8. La reunión de Sebastopol, California, coordinada por Tim O’Reilly y Carl Malamud y con el patrocinio de Sunlight Foundation, Google y Yahoo, constituye un hito en la materia, pues en ella más de treinta organizaciones desarrollaron los Principios del Open Government Data, que han llegado a ser el punto de partida para la apertura de información y registros gubernamentales.

9. Disponible en: http://opengovdata.org/. 
- No propietaria: La información no debe estar en formatos asociados a alguna entidad o bien que requieran de algún tipo de herramienta propietaria para su uso.

- Licenciamiento libre: La información no debe estar sujeta a ningún derecho de autor, patente, marca, regulación o secreto que permita restricciones o privilegios de uso.

A esos ocho principios originales, se han añadido posteriormente los siete principios siguientes:

- En línea y gratis: La información no es realmente abierta pública si no se encuentra disponible en internet sin costo, o al costo marginal de reproducción.

- Permanencia: La información debe estar disponible en un sitio de internet estable por tiempo indefinido.

- Procedencia y confianza: El contenido publicado debe ser firmado digitalmente o incluir la certificación de la fecha de publicación o creación, con el objeto de asegurar su autenticidad e integridad.

- Presunción de apertura: Por regla general, la información así dispuesta no tiene barreras para reutilización y consumo.

- Documentada: Se debe incluir información sobre el formato, grado de actualización y significado de información.

- Segura: Se deben usar formatos de datos que no incluyan contenidos autoejecutables.

- Diseñada con aportes públicos: Idealmente, la información debe recibir aportes para definir el diseño de su puesta a disposición de manera que pueda ser conocida y comprendida por la mayor cantidad de personas. La opinión y participación de los usuarios de la información es crucial para definir la forma de difundir la información pública.

Es importante destacar que conforme ha avanzado el tiempo y ya en conceptualizaciones más avanzadas, la apertura de datos gubernamentales se concibe como una verdadera filosofía o doctrina que sustenta la «democratización de la información», y que considera que los datos públicos pasan por un ciclo de vida o flujo de procesamiento, en el cual son recogidos, estructurados y enlazados por los distintos agentes, para permitir su distribución oportuna e incentivar luego la supervisión o corrección por parte del público que los utiliza. Esta nueva conceptualización recibe el nombre de datos abiertos enlazados u open linked data y constituye, como se señala más adelante, la esencia de la web semántica. 


\section{Gratuidad de la información legislativa}

No obstante el significativo traslado de los servicios de información legislativa desde el sector privado al público que se ha observado en los últimos años, no debe entenderse que el debate sobre la titularidad del servicio y su costo está acabado, puesto que durante décadas entes de carácter privado asumieron la tarea de publicar, sistematizar, clasificar e indizar esta información.

Muchos de estos entes incluso carecen de toda autorización y responsabilidad legal, como por ejemplo en Chile, en que los textos legales son distribuidos por vendedores callejeros en lugares contiguos a los principales puntos públicos del país (tribunales, municipios, correos, etcétera). Otros lo hicieron bajo el amparo de los propios Estados, quienes incluso les proporcionaban los textos jurídicos básicos, al tenor de la Recomendación (83) 33 F del Consejo Europeo.

Sin embargo, al menos en la mayoría de los países europeos, hoy es el Estado quien administra los servicios de información legislativa y los proporciona sin costo a los ciudadanos destinatarios de las normas.

Así lo recoge el propio Consejo Europeo en su Recomendación 3F (2001), al señalar textualmente: «Le simple accès aux textes dans la base de données législatives devrait être gratuit pour le particulier»o «el acceso simple a los textos en las bases de datos legislativas deberá ser gratuito para los particulares» (Traducción libre de la autora). Lo anterior, en gran parte impulsado por un sentido jurídico general que aboga por la gratuidad, esencialmente atendido el carácter, valor e interés público de la información legal.

Bajo esta mirada ya no es posible concebir estos servicios en un contexto mercantil, sino que se debe entender que los servicios de información legislativa tienen carácter público y deben ser provistos de forma gratuita por el Estado para asegurar los principios de publicidad, seguridad jurídica e inexcusabilidad del conocimiento de la ley. Se insiste, además, que los esfuerzos realizados en este sentido nunca resultarán costosos, pues es más oneroso económica y socialmente el desconocimiento de las normas.

En este sentido se han pronunciado Fernando Pablo y Rivero Ortega (2001: 41-50), al expresar que sería del todo inaceptable que se vendan estos contenidos compuestos por informaciones que tienen una naturaleza indiscutiblemente pública. El Estado no puede explotarlos comercialmente porque se está ante un servicio público que realiza un principio constitucional y una exigencia básica del sistema jurídico. Del mismo modo lo hace Menéndez Menéndez (2004: 20) al llamar la atención sobre la necesidad de que los poderes públicos asuman esta actividad como una tarea urgente $\mathrm{y}$ de interés nacional.

La doctrina en general sostiene que se debe evitar generar una barrera de entrada al conocimiento ciudadano de la ley o crear una desigualdad entre quienes pueden 
pagar servicios de información legal (normalmente el mundo experto) y aquellos ciudadanos que no se lo puedan permitir, todo lo cual atentaría contra el principio de igualdad reconocido universalmente a nivel nacional e internacional.

Todo lo anterior no significa que las empresas privadas no puedan desempeñar en este ámbito importantes funciones ofreciendo valor agregado en la cadena informativa: por ejemplo, estableciendo relaciones entre los textos de las normas jurídicas y otra información jurídica, como la doctrina que los interpreta o la jurisprudencia que los aplica, o bien desarrollando sistematizaciones temáticas o mejores sistemas de búsqueda de las normas. En este ámbito, es destacable el aporte de numerosas entidades, especialmente en lo que refiere a la actividad de construcción de repertorios de legislación vigente clasificados temáticamente.

En definitiva, en razón de la apertura exigida para este tipo de información y el principio de igualdad en el acceso a la misma, se entiende que el servicio que la otorgue debe ser público y gratuito. El Estado debe garantizar que el ciudadano pueda conocer con certeza las normas vigentes.

\section{Oficialidad}

Es un hecho reconocido actualmente en el mercado de los servicios legislativos que el principal motor de la demanda de esta información son los propios textos legales. Así entendido, uno de los principales retos en esta materia es garantizar el acceso y la preservación a largo plazo de los contenidos de esos textos. De aquí surge la preocupación por garantizar la autenticidad, validez, integridad y conservación de los mismos.

En este ámbito, la discusión se centra en el carácter oficial del texto de la ley y la seguridad jurídica que éste debe proporcionar a los ciudadanos y a los operadores jurídicos.

Es interesante lo que señala Biglino Campos (1993: 172) acerca de esta materia, pues refiere que en los países anglosajones «el único texto que es realmente indiscutible para los tribunales de justicia es el texto auténtico de la ley». Al respecto, agrega:

En Gran Bretaña, desde el Acta de 1911, enmendada en 1949, el certificado del speaker es determinante a todos los efectos y no puede ser cuestionado por ningún tribunal (sección 3). Por otra parte, desde 1849 la Imprenta Real elabora dos copias impresas autentificadas por el clerk, una de las cuales es conservada en el Public Record Office. El texto publicado de la ley da fe sin que sea necesario probar su existencia, aunque es posible confirmar la exactitud del ejemplar publicado mediante su comparación con los registros del Parlamento [...]. Algo similar ocurre en Estados Unidos. Únicamente la impresión de la ley como «enrolled bill», certificada por los oficiales de la Cámara y conservada en los archivos del Gobierno por el secretario de Estado, constituye la copia auténtica de las leyes [...]. Desde la Printing and Binding Act de 12 de enero de 1895 (sección 73), la Secretaría de Estado publica los Statutes 
at Large que entre otras cuestiones contienen las leyes elaboradas por el Congreso. Expresamente, el Acta declara que los Statutes constituyen la evidencia legal de las leyes en ellos contenidas para todas las Cortes de Justicia [...]. En caso de conflicto, el texto auténtico de la ley prevalece sobre el texto publicado [...]. En un sentido similar, la Constitución irlandesa, en su artículo 25.5, dispone que, tras la firma y promulgación por el presidente de la República, las leyes se registran en el Tribunal Supremo y constituyen prueba concluyente de los preceptos de la ley en cuestión (Biglino Campos, 1993: 173).

A partir de lo anterior, aparece la pregunta: ¿cuál es el texto oficial de la ley?

De forma generalizada, en nuestros sistemas se puede responder a esta pregunta señalando que es aquél que, habiendo cumplido con las etapas y formalidades dispuestas por el proceso de formación de la ley, se publica en el medio establecido para tal efecto por el propio ordenamiento jurídico, pudiendo agregar que, por regla general, también esto último se hará en nuestros ordenamientos mediante la inserción en un periódico al que se otorga el carácter de oficial, denominado indistintamente, Diario, Boletín o Gaceta Oficial. Aunque es posible igualmente que la propia norma pueda disponer su publicación en un medio distinto de aquéllos y en tal caso la publicación también revestirá el carácter de oficial.

Al respecto, en materia de publicación oficial, la realidad europea muestra los casos del Riigi Teataja ${ }^{10}$ de Estonia, desde 2001; el Journal Officiel de Francia, ${ }^{11}$ desde 2004; la Gazzetta Ufficiale de Italia, ${ }^{12}$ desde 2009; y el Boletín Oficial en España (BOE), ${ }^{13}$ desde 2009, en que las versiones en papel y electrónica son igualmente válidas. En cambio, como ya se adelantó, en los casos del Bundeskanzleramt de Austria, desde 2004; el Post-Och Inrikes Tidningar de Suecia, desde 2007, y EUR-LEX en la Unión Europea, desde 2013, su versión electrónica es considerada como único formato auténtico. En España, por su parte, además de la edición electrónica del BOE existe una impresa, obtenida de aquélla, con idénticas características y contenido. Esta edición impresa tiene la finalidad de:

- asegurar la publicación del BOE, cuando por una situación extraordinaria y por motivos de carácter técnico no resulte posible acceder a su edición electrónica, $\mathrm{y}$

- garantizar la conservación y permanencia del diario oficial del Estado y su

10. Riigi Teataja, Gaceta Oficial de la República de Estonia. Disponible en https://www.riigiteataja.ee/ en/.

11. Journal Officiel de la République Française (JORF), Diario Oficial de la República Francesa. Disponible en http://www.journal-officiel.gouv.fr/.

12. Gazzeta Ufficiale, Gaceta Oficial de la República de Italia. Disponible en http://www.gazzettaufficiale.it/.

13. Boletín Oficial del Estado Español (BOE). Disponible en http://www.boe.es/. 
continuidad como parte del patrimonio documental impreso de la Administración General del Estado.

Un problema adicional que se enfrenta en el tema del carácter oficial de las normas legales es el referido a los textos consolidados, refundidos, ordenados o únicos, que obedecen a un acto de consolidación oficial y por tanto poseen fuerza de ley.

En algunos sistemas, los textos son validados en los propios textos constitucionales que entregan esta facultad al Ejecutivo, quien debe elaborarlos y publicarlos, y por tanto su fuerza legal se deriva de esta delegación constitucional al Ejecutivo y su oficialidad de la publicación de los mismos. Sin embargo, como se observa en la práctica, al menos en Chile, la deficiencia en la gestión de la elaboración y aprobación de estos textos por el Ejecutivo y en su coordinación con el Legislativo ha traído aparejado un envejecimiento prematuro de la consolidación elaborada y al mismo tiempo la privación al Parlamento de su poder legislativo. A modo de ejemplo se puede citar lo que ocurrió con el Estatuto Administrativo, principal normativa regulatoria de la actividad de los funcionarios públicos en el país, cuyo texto refundido fijado por el Decreto con Fuerza de Ley $29(2014)^{14}$ del Ministerio de Hacienda no incorporó las normas de acoso sexual dictadas por la Ley 20.005 (2005). ${ }^{15}$ Evidentemente, el Poder Ejecutivo no se enteró de la modificación trabajada en el tiempo intermedio. En 2012, el Congreso Nacional dictó la Ley 20.607, ${ }^{16}$ que incorporó las modificaciones expresamente.

En otros sistemas, estos textos son elaborados por iniciativa propia y sin esta delegación, incluso por los propios órganos legislativos, y por tanto carecen de carácter oficial. Así por ejemplo EUR-LEX, el portal web de la Comunidad Europea que realiza esta tarea, advierte especialmente de ello con un aviso que establece:

Esta presentación en internet pretende contribuir a la acción general emprendida por la Comisión para hacer más accesible el derecho comunitario. Se advierte al usuario que los textos consolidados se presentan a título informativo; por consiguiente, no crean ningún derecho ni ninguna obligación distintos de los que se derivan de los textos jurídicos legalmente adoptados y publicados; éstos son los únicos textos auténticos.

Lo propio ocurre con el Sistema Ley Chile de la Biblioteca del Congreso Nacional de Chile, ${ }^{17}$ que también advierte que sus textos consolidados no son oficiales.

14. Decreto con Fuerza de Ley 29 (2005) del Ministerio de Hacienda. Disponible en http://bcn.cl/1njcg. 15. Ley 20.005, que Tipifica y Sanciona el Acoso Sexual, publicada el 18 de marzo de 2005. Disponible en http://bcn.cl/1mocy.

16. Ley 20.607, Modifica el Código del Trabajo, sancionando las prácticas de acosos laboral, publicada el 8 de agosto 2012. Disponible en http://bcn.cl/1mo3s.

17. Ley Chile. Disponible en https://www.leychile.cl/. 
El problema anterior demuestra la importancia de conocer si se está o no ante un texto oficial que asegure la autenticidad, validez e integridad de la información.

En el ámbito, también se presenta la discusión sobre si cualquier alteración o transformación gráfica podría modificar la percepción cognitiva humana del contenido normativo y legal y por tanto la integridad del texto.

Otro aspecto a considerar es la conservación y almacenamiento a largo plazo en formatos reconocibles, pues no debe olvidarse que la información legislativa debe conservarse en el tiempo, pues forma parte del patrimonio legislativo de una nación.

A partir de lo anterior y en concreto, siguiendo a Palmirani y Vitali (2012), que han venido trabajando desde largo tiempo en estas materias, el conjunto de propiedades que debe asegurar el texto oficial son las siguientes.

\section{Validez}

Esta garantía se otorga una vez que se han aplicado todas las reglas normativas y administrativas, incluida la firma electrónica, para generar un documento vinculante, ejecutable y legal.

\section{Autenticidad}

Esta garantía permite declarar que el documento está aprobado por una autoridad facultada, a través de una cadena oficial de poder y funciones, y que el contenido está conforme a la versión original del documento, es decir, la versión que los autores, a través de sus poderes soberanos, querían y decidieron emitir.

Hasta ahora esa garantía venía dada por la firma del autor del documento; sin embargo, en los documentos electrónicos se configura hoy en día, en la mayoría de los casos, a través de una serie de elementos de seguridad determinados en lo que se conoce como firma electrónica reconocida.

\section{Integridad}

Otorga la garantía que el documento electrónico no ha sufrido alteraciones en lo que se refiere a las informaciones en él contenidas durante la transmisión o intercambio del mismo, una vez que se encuentra debidamente autenticado y también permite detectar cualquier cambio que pueda haberse interpuesto entre las copias digitales del documento único y el archivo maestro original.

\section{Disponibilidad operacional 24/7}

Como se ha dicho, la publicación electrónica de la ley constituye un avance como instrumento para dar publicidad a las normas jurídicas y cumplir con las aspiraciones de 
mayor eficacia de su comunicación. Afortunadamente, se observa una tendencia creciente hacia los servicios en línea de esta información legislativa, que según se ha visto incluso han venido a reemplazar la publicación oficial impresa en algunos países.

En estos servicios, la totalidad del proceso de publicación debe estar implementado de tal modo de garantizar, en el corto, mediano y largo plazo, un alto nivel de disponibilidad de las plataformas técnicas de servicios y de producción, y de los recursos humanos asociados, las veinticuatro horas del día de los siete días de la semana.

A mayor abundamiento, y dada la evolución y penetración de las aplicaciones móviles, un nuevo estándar es el desarrollo de servicios altamente especializados, convergentes, adaptables, disponibles en diversos dispositivos y para múltiples plataformas.

\section{Licenciamiento libre}

Un elemento fundamental del acceso a la información legislativa lo constituye el que no esté sujeta a ningún tipo de copyright, patente u otro tipo de derecho; dicho de otro modo, que las condiciones legales bajo las cuales está disponible esta información permiten su uso, redistribución, modificación, compilación o propagación ampliamente, sin limitación alguna y bajo cualquier propósito.

Lo anterior se funda en el claro carácter de información de dominio público de los contenidos de las normas legales, pues como señala el documento elaborado por Uhlir (2004: viii) para Unesco, reviste el carácter de información de dominio público, por un lado, la información que queda al margen del ámbito de protección legal (derechos de autor en general) y, por otra parte, la información de carácter intrínsecamente pública, es decir, determinados tipos de información producidos por los poderes públicos en el ejercicio de sus funciones y que se consideran un bien público. Por lo anterior, se puede señalar que, en efecto, casi nadie discute hoy en día el carácter público de la información contenida en estos textos legislativos.

En aplicación de lo dispuesto en el Convenio de Berna (1886), ${ }^{18}$ esta información se encuentra excluida como objeto de propiedad intelectual en la mayoría de las legislaciones. El Convenio señala que «queda reservada a las legislaciones de los países de la Unión la facultad de determinar la protección que han de conceder a los textos oficiales de orden legislativo, administrativo o judicial, así como a las traducciones oficiales de estos textos». España y México lo hacen expresamente. ${ }^{19}$

18. Convenio de Berna para la Protección de las Obras Literarias y Artísticas, 1886. Disponible en http://bit.ly/2ADwknG.

19. En España, el artículo 13 de la Ley de Propiedad Intelectual (Real Decreto Legislativo 1/1996) señala: «No son objeto de propiedad intelectual las disposiciones legales o reglamentarias y sus correspondientes proyectos, las resoluciones de los órganos jurisdiccionales y los actos, acuerdos, deliberaciones y dictámenes de los organismos públicos, así como las traducciones oficiales de todos los textos anteriores» (Real Decreto Legislativo 1/1996. Disponible en: $h t t p: / / b i t . l y / 2 A E y 7 I Q)$. En México, el artículo 14 de 
En el caso de Chile, si bien no se establece expresamente, después de haberse discutido por años, durante el debate en la tramitación de la Ley 20.435 que modificó la Ley 17.336 de Propiedad Intelectual, ${ }^{20}$ se zanjó esta discusión, señalando que los textos legales como expresión de actos legislativos no son objetos de protección de la propiedad intelectual (Historia de la Ley 20.435: 520, 545).

\section{Confidencialidad de información legal bajo reserva o secreto}

La doctrina jurídica admite justificación jurídica a la posibilidad de la reserva de determinadas normas en circunstancias calificadas. Establecido lo anterior, y desde el punto de vista de una efectiva gestión de información, la acción debe estar orientada a la configuración legislativa expresa de las causales, así como a la implementación técnica de mecanismos adecuados para asegurar esa confidencialidad, especialmente si se considera la realidad que impone la publicación electrónica de la ley.

En el plano de su configuración jurídica, se requiere que la legislación y la jurisprudencia reconozcan causales de reserva o secreto legítimamente válidas, las que, según expresa la doctrina especializada, pueden estar fundadas en la seguridad de la nación, el interés nacional o muy especialmente en la protección de ciertos derechos fundamentales como es, por ejemplo, la protección de datos personales, límites que se han considerado por la teoría del derecho a la información. Lo anterior significa que el problema de la reserva esté resuelto en el ordenamiento jurídico en el que se aplica, esto es, el sistema legal regula, autoriza o prohíbe este tipo de leyes o establece de modo particular y excepcional la reserva o secreto para determinados actos legislativos y administrativos.

En el ámbito de la implementación, al considerar, como se ha reiterado, la realidad de la publicación electrónica, se debe regular, diseñar e imponer medidas de reserva, acceso restringido e incluso la desindexación de los contenidos publicados y por supuesto amplias y efectivas medidas de seguridad que permitan proteger aquella información en las condiciones y plazos requeridos.

Un ejemplo de lo anterior se encuentra en la legislación francesa, la que para asegurar el derecho fundamental a la protección de los datos personales y siguiendo las

\footnotetext{
la Ley Federal del Derecho de Autor, expresa: «No son objeto de la protección como derecho de autor a que se refiere esta Ley: viii) Los textos legislativos, reglamentarios, administrativos o judiciales, así como sus traducciones oficiales. En caso de ser publicados, deberán apegarse al texto oficial y no conferirán derecho exclusivo de edición; sin embargo, serán objeto de protección las concordancias, interpretaciones, estudios comparativos, anotaciones, comentarios y demás trabajos similares que entrañen, por parte de su autor, la creación de una obra original» (Ley Federal del Derecho de Autor. Disponible en http:// bit.ly/2yowrxh).

20. Ley 17.336 de Propiedad Intelectual, publicada el 20 de octubre de 1970. Disponible en http://bcn. cl/1uv3k.
} 
recomendaciones de la Comisión Nacional de Informática y Libertades, en el Décret 2004-459 (2004), ${ }^{21}$ recoge una serie de actos legislativos, de carácter individual, que no pueden ser objeto de publicación en la versión electrónica del Diario Oficial. Se encuentra aquí evidencia de una medida adecuada para proteger lo que ha venido configurándose como el derecho al olvido digital.

$\mathrm{Al}$ respecto, se coincide con Cotino (2014), que señala que

hay que regular la difusión de contenidos en los boletines oficiales, así como los tablones electrónicos. La legislación habría de reconocer facultades a los organismos de boletines oficiales para analizar y en su caso bloquear publicaciones que generen innecesario impacto en la privacidad.

\section{Preservación de la información}

El acceso a la información legislativa es un requisito para asegurar su recuperación en el futuro. Este acceso debe persistir en el tiempo, incluso más allá de varias generaciones.

Sin embargo, los cambios sociales impulsados por la sociedad red hacen difícil la conservación de esta información debido entre otras causas al acelerado ritmo de su crecimiento y a los rápidos y sucesivos cambios en los formatos y soportes informacionales, que como se ha dicho transitan completamente hacia la publicación electrónica.

Si no se hace nada, muchos documentos legales en formato electrónico no sobrevivirán o serán completamente inaccesibles dentro de muy poco. El resultado será una pérdida permanente para la memoria legislativa de la humanidad.

Por lo anterior, es preciso abordar este desafío y asegurar la preservación de esta información bajo condiciones que garanticen su oficialidad, disponibilidad permanente y la mantención de su confidencialidad de ser necesario.

Desde el punto de vista de la gestión documental, el estándar exige la conservación del documento a corto, mediano y largo plazo, lo que garantice la preservación de los atributos fundamentales que les confieren su valor legal e informativo, y su integración con el contexto, tanto con el organismo o unidad de gestión que los produjo, como con la tecnología con que se produjeron.

Para este efecto, se debe asegurar tanto el almacenamiento del documento a largo plazo, como el archivo de toda la información relacionada con la historia de ese documento. La normativa de la International Organization for Standardization, ISO

21. Décret 2004-459 (2004), Fixant les categories d'actes individuels ne pouvant faire l'objet d'une publication sous forme électronique au Journal officiel de la République française. Disponible en http:// bit.ly/2yohkUF. 
15489:2001 sobre gestión de registros y archivos, puede ser aplicada con éxito para alcanzar este estándar.

En otras palabras, la preservación implica la conservación de toda la información con la cual poder rastrear el ciclo de vida completo del documento, lo que también se denomina trazabilidad, y que tendrá gran relevancia también, como se señala más adelante, para la gestión de calidad de los procesos involucrados.

\section{Seguridad de la información}

Es claro que hoy en día en el ámbito de la información existen numerosos riesgos. En la sociedad red no se habita un mundo de equipos ni conexiones fijas, tenemos gran parte de nuestra información en la nube, las relaciones transfronterizas y la vigilancia telemática son parte de nuestro diario vivir. Es también claro que los riesgos son más variados, complejos y difíciles de identificar.

Si se considera un sistema de información que almacena la información legal de un país, es esencial la protección de esa información, si tenemos en cuenta la importancia de sus contenidos como información de alto valor público con fuerte impacto en el comportamiento de la ciudadanía y que resulta fundamental para el desarrollo de la vida de las personas. Es perentorio entonces que estos sistemas adopten medidas de protección de esta información, atendida la complejidad e importancia de la misma para nuestra cultura jurídica.

Desde la mirada de la gestión informacional que se revisa, la protección de la información almacenada y provista por estos servicios se logra a través del estándar o principio que se conoce con el nombre de «seguridad informática» $\mathrm{o}$ «seguridad de la información», y que se refiere al conjunto de normas, sistemas, procedimientos, herramientas y recursos humanos orientados a garantizar la oficialidad, disponibilidad, confidencialidad y preservación de la información legislativa automatizada.

Siguiendo al profesor Saarenpää (2005), se puede afirmar que la seguridad de la información es un componente ineludible de una sociedad red, donde las infraestructuras protejan efectivamente los derechos de los individuos en un Estado constitucional de derechos. En general, la seguridad comprende las medidas técnicas y de organización adecuadas para la protección de la información, contra la destrucción accidental o ilícita, la pérdida accidental y contra la alteración, la difusión o el acceso no autorizados, cualquiera sea el método de tratamiento. Estas medidas deben aplicarse en niveles o en relación con los riesgos que presente el tratamiento y con la naturaleza de los datos que deban protegerse: obviamente los datos confidenciales o con reserva requerirán mayor nivel de protección. Es también claro que las medidas deben alcanzar en su totalidad la infraestructura, hardware y software del servicio de información, e incluso las redes de comunicación a través de las cuáles ella se transmite. 


\section{Calidad de los procesos}

Los sistemas de información legal deben ser capaces de asegurar a sus usuarios la calidad de los contenidos ofrecidos. Para tal efecto, los estándares internacionales exigen que sus procesos estén orientados bajo una política de calidad, con objetivos, procedimientos y actividades definidas, medibles y con trazabilidad observable en cada etapa del proceso. Los roles y responsabilidades de quienes participan en los procesos deben ser definidos y asociados a un perfil para el cual se han determinado las competencias requeridas, las cuales deben evaluarse periódicamente. Y del mismo modo, periódicamente se debe establecer un procedimiento que recoja las quejas y los requisitos de sus usuarios para prevenir, corregir o mejorar en forma continua. La certificación de calidad de los procesos que ofrece la normativa de la International Organization for Standardization, ISO 9001:2015, puede ser un aliado eficiente para cumplir con este estándar.

\section{Modelo de servicio: La web semántica legislativa}

Tal como hemos señalado anteriormente, la sociedad red caracterizada por la creciente expansión de internet y, en concreto, de la World Wide Web, ha impulsado un cambio tecnológico trascendental para el derecho a la información legislativa.

Según se observa, la web se ha convertido en interfaz prácticamente obligatoria y ha alterado radicalmente el mercado de los contenidos en cuanto a la producción, almacenamiento, recuperación y comunicación de esta información.

Como constataron Dalgleish y Hall, internet «se ha establecido como un medio para la más amplia diseminación de información, al punto que en breve espacio de tiempo la producción de materiales electrónicos ha excedido largamente a la de publicaciones impresas» (Dalgleish y Hall, 2000: 104).

Del mismo modo, se puede decir que se ha convertido en plataforma eficaz para la distribución de contenidos jurídicos y en una posibilidad real para dar respuesta a los requerimientos originados por el fenómeno de contaminación legislativa y a la demanda de mejor y más fácil acceso a la legislación, no sólo de los especialistas, sino de los propios ciudadanos obligados por las normas jurídicas que integran el ordenamiento.

En efecto, las bases de datos jurídicas que vieron su aparición en la década de los sesenta sufren, a partir de la segunda mitad de la década de los noventa, una alteración esencial producto del advenimiento de las TIC y de internet. Con ello, también el modelo de servicio cambia radicalmente y los prestadores deben realizar la inevitable migración de sus bases de datos al nuevo entorno, o como ocurrió en algunos casos, abandonar el ejercicio de esta actividad, la que como se ha dicho en muchas instancias pasó a ser asumida por las entidades públicas. 
El éxito de la World Wide Web en esa primera época se basó en ofrecer una solución sencilla y abierta al problema de la publicación electrónica, pues se centró en transmitir documentos de forma no sólo eficaz, sino, sobre todo, muy eficiente, gracias a la codificación electrónica.

Según García Marco, la comunicación mediante documentación digital en red aporta en la época cinco ventajas que superan la de la documentación en papel:

Velocidad -inmediatez, de hecho-, economía de transporte y almacenamiento, una disponibilidad universal y un medio compatible con cualquier tipo de documento - sonido, texto, imágenes fijas, video, interactivos y sus combinaciones- y de carácter convergente - proporciona una plataforma para medios tanto privados como públicos, personales o institucionales, y tiene un carácter multicanal- (García Marco, 2009: 63).

Según el mismo autor, como consecuencia de lo anterior, la World Wide Web se convirtió rápidamente en una plataforma integral de publicación, almacenamiento y recuperación de la información, y, progresivamente, de autentificación, organización y conservación de la información.

En el mismo sentido se pronuncian Barité y López-Huertas (2004: 30-31), quienes reconocen como ventajas de la World Wide Web las siguientes: su disponibilidad permanente; la consulta desde cualquier lugar; la inmediatez del acceso; la progresiva compatibilización y uniformización de herramientas, de funciones y de íconos identificatorios; la enorme dimensión de información a la que puede accederse, incomparable en relación con su correlato impreso; y la fiabilidad y credibilidad de los sitios institucionales y gubernamentales.

Los mismos autores reconocen, sin embargo, también algunas desventajas: la información en internet tiene menos estabilidad y puede desaparecer o modificarse sin mayores garantías; el acceso a la red implica una inversión que no todo el mundo está en condiciones de hacer, y una capacitación que no todos poseen; la actualización de documentos causa la pérdida de fuentes o versiones originales; muchos sitios organizan su información pobremente, y ocasionan problemas de búsqueda y recuperación. Otros repiten información tomada de otras fuentes sin mayor análisis, y aún en otros casos la fiabilidad y la credibilidad de la información disponible no son mínimamente satisfactorias. También que la información con algún valor económico tiene un precio que no puede pagar todo el mundo, lo que pone barreras económicas a datos de interés social.

Estas limitaciones, unidas a las que referían a la representación hiper e intertextual y al procesamiento automático de los contenidos, dieron rápidamente pie a una completa y trascendental evolución de la World Wide Web, materializada en la web semántica.

A continuación, se analiza su concepto y las principales tecnologías que la apoyan. 


\section{Concepto}

En 2001, la World Wide Web Consortium $\left(\mathrm{W}_{3} \mathrm{C}\right)^{22}$ lanzó el ambicioso y prometedor proyecto de la web semántica (del inglés semantic web), que refiere a la «web de los datos» y que tiene como objetivo último permitir a las computadoras hacer el trabajo más fácil y útil y desarrollar sistemas que puedan apoyar la confianza en las interacciones de la red. En otras palabras, que las personas accedan en un lugar de la red a la información que encuentran en las bases de datos.

La página web del $\mathrm{W}_{3} \mathrm{C}$ precisa que el creador de la web, Tim Berners-Lee, intentó desde el principio incluir información semántica en su creación, pero por distintas razones esto no fue posible sino hasta ahora. Para el creador, «la Web Semántica es una extensión de la web actual, en la cual se da a la información un significado bien definido para permitir que los computadores y la gente realicen un trabajo cooperativo». Como se verá, para hacer esta web de datos una realidad, es importante contar con una enorme cantidad de datos disponibles en la red en un formato estándar, accesible y manejable por las herramientas de la web semántica. Además, no sólo se necesita acceso a los datos, sino que éstos deben estar relacionados de manera de crear una red de datos, en oposición a una mera colección o conjunto de datos. Este conjunto de datos relacionados entre sí en la web es denominado como linked data y en la visión del $\mathrm{W}_{3} \mathrm{C}$ constituye la esencia de la web semántica. Así entendida, la web semántica no se trata sólo de poner los datos en línea. Se trata de hacer enlaces para que una persona o una máquina puedan explorar esa red de datos.

$\mathrm{Al}$ igual que la web de hipertexto, la web de los datos se construye con documentos. Sin embargo, a diferencia de la web de hipertexto, donde los vínculos son relaciones anclas entre documentos, en la web semántica existen relaciones arbitrarias entre los datos que permiten acceder a información no buscada originalmente, pero relacionada y disponible en el conjunto de datos descritos previamente.

De este modo, la web semántica constituye un esfuerzo por crear un marco de representación y organización de la información contenida en documentos y compartida en internet a partir de sus relaciones profundas en el plano del significado, es por ello que se utiliza el vocablo semántico, que según la Real Academia Española de la Lengua es perteneciente o relativo a la significación de las palabras. En la práctica, lo que se hace es añadir metadatos semánticos y ontológicos a la World Wide Web. Esas informaciones adicionadas, que describen el contenido, el significado y la relación

22. World Wide Web Consortium $\left(\mathrm{W}_{3} \mathrm{C}\right)$, disponible en http://www.w3.org/Consortium/. El World Wide Web Consortium $\left(\mathrm{W}_{3} \mathrm{C}\right.$ ) es una comunidad internacional reunida en torno a desarrollar los estándares de la web. Esta comunidad liderada por Berners-Lee y su CEO Jeffrey Jaffe se ha fijado como misión guiar la web hacia su máximo potencial y para ello desarrollar protocolos y pautas que aseguren su crecimiento a largo plazo. 
de los datos, se proporcionan de manera formal, para que así sea posible evaluarlas automáticamente por máquinas de procesamiento. En definitiva, el objetivo es ampliar la interoperabilidad entre los sistemas informáticos usando programas computacionales que buscan información sin intervención humana y con ello producir la integración de información publicada en la web. Estos programas son denominados por los especialistas como gestores de contenido.

Las tecnologías de web semántica permiten a las personas crear repositorios de datos en la web, construir vocabularios y escribir las reglas para el manejo de esos datos. A través de ellas, se incorporan descripciones explícitas de los recursos de la web, ya sean éstos catálogos, formularios, mapas u otro tipo de objeto documental. De esta forma, el contenido queda revelado o disponible, como los datos de una base de datos accesibles por web, o las etiquetas contenidas en el documento. Son esas etiquetas las que permiten que los gestores de contenidos interpreten los documentos y realicen procesos inteligentes de captura y tratamiento de información.

En concreto y en un análisis simple, la web semántica se plantea como un esquema para identificar y procesar automáticamente los datos que contiene la información. Sin embargo, se debe hacer presente que, como señala García Marco, la representación en niveles de sucesiva integración y control que incorporan las tecnologías de la web de datos «se asemeja a la estructura real de los sistemas cognitivos humanos y permite una representación del conocimiento que va más allá del simple procesamiento de la información» (García Marco, 2009: 68).

Introducido el concepto de web semántica, se revisa ahora su aplicación al ámbito de la información legal, en lo que se denomina la web semántica legislativa. Según el mismo García Marco se puede definir como:

Un sistema de información, comunicación y documentación de carácter abierto, distribuido e interoperable en la internet, dotado de las características avanzadas que proporciona la web semántica, que evoluciona y se desarrolla con objeto de resolver de forma integrada y sinérgica las necesidades del ciclo completo de la actividad legislativa y de todos sus agentes (García Marco, 2009: 69).

Dada la intrínseca relación entre documento y legislación, en que esta última se materializa preferentemente en documentos, la World Wide Web, esencialmente basada, como se señaló, en documentación, ha apoyado desde sus inicios la producción, recuperación y difusión de la información legislativa, con lo que se ha convertido paulatinamente en acceso básico e imprescindible para la búsqueda y recuperación de esta información por los profesionales del derecho, desde las diversas bases de datos y repositorios jurídicos.

Con el correr del tiempo, el gran reto lo constituyó dar valor público y relacionar estos repositorios de manera de integrar la información jurídica vinculada, todo ello con el objeto de dar acceso efectivo, así como lograr la reducción de costos de proce- 
samiento y difusión de la información legislativa. Bajo este contexto, desde el punto de vista de la gestión informacional que se analiza, la web semántica legislativa debe entenderse como algo más que hacer recuperable y navegable esta información de forma más eficaz y eficiente, objetivo este último al que no puede renunciar.

Esta gestión también debe comprender la tarea sistemática de organizar el conocimiento de la realidad social y de las técnicas jurídicas que se utilizan para estructurarla dentro de marcos políticos, tal y como aparecen de forma subyacente en la propia legislación, de manera que este enorme conjunto de documentos sea capaz de responder de forma cada vez más sencilla a preguntas cada vez más inteligentes y sofisticadas. Es precisamente gracias a las tecnologías de representación que ofrece la web semántica, que es posible intentar organizar y representar la información legislativa a través de una estructura intermediadora que ponga en contacto el contenido del cuerpo normativo en permanente expansión con las necesidades de conocimiento de esa información que tienen los actores de la sociedad.

Es desde esta perspectiva en que cobra sentido hablar de representación y organización del conocimiento legislativo y no sólo de la información legislativa, como se verá con mayor claridad al analizar las ventajas de la web semántica.

\section{Tecnologías y herramientas de la web semántica}

Para el logro de sus objetivos, la web semántica legislativa se ha valido de las siguientes tecnologías: el documento estructurado (XML) y la definición del esquema documental (DTD, XML Schema); el nivel de relaciones entre metadatos (RDF) y la definición de esquemas de metadatos (RDF Schema); y finalmente, la modelización de dominios de conocimientos (OWL).

De acuerdo con lo anterior, se puede decir, en palabras de Codina y Rovira (2006), que la infraestructura de esta web semántica se sustenta en tres elementos: XML, metadatos y ontologías, los que se analizan a continuación.

\section{Extensible markup language (XML)}

XML, el lenguaje de marcación estándar promovido desde 1998 por el W3 $\mathrm{C}$ y adoptado ampliamente a nivel mundial para representar datos y documentos y almacenarlos en forma legible, es indudablemente la herramienta componente de la web semántica que mayor repercusión ostenta hasta el momento. El concepto principal del lenguaje XML es el de envolver el texto con elementos de anotación, llamados etiquetas o tags, que califican el texto.

XML es pura sintaxis, sin una semántica predefinida. Esto permite a los diseñadores de documentos crear su propia semántica. La descripción de los datos se consigue a partir del apoyo en reglas de estructuras de datos. En general, las estructuras de 
datos para XML se materializan en documentos DTD (data type definition) o a través de XSD (XML Schema).

En términos simples, es un conjunto de reglas que permiten definir etiquetas semánticas que, aplicadas a un documento, permiten su organización en diferentes partes. Algunas de las principales ventajas que tiene el clasificar la información bajo este sistema son:

- Es una arquitectura más abierta y extensible.

- Otorga mayor consistencia, homogeneidad y amplitud de los identificadores descriptivos del documento con XML en comparación a las etiquetas del HTML.

- Permite la integración de los datos de las fuentes más dispares. Se podrá hacer el intercambio de documentos entre las aplicaciones tanto en el propio PC como en una red local o extensa, como veremos al tratar la interoperabilidad.

- Los motores de búsqueda devuelven respuestas más adecuadas y precisas, ya que la codificación del contenido web en XML consigue que la estructura de la información resulte más accesible.

- Permite el desarrollo de manera extensible de las búsquedas personalizables y subjetivas para robots y agentes inteligentes. También conlleva que los clientes web puedan ser más autónomos para desarrollar tareas que actualmente se ejecutan en el servidor.

- Permite la exportabilidad a otros formatos de publicación.

En el ámbito legislativo, el uso de XML es ideal para representar los documentos legales, pues éstos tienen una estructura bien definida, que es sistemática y estandarizada, hay partes obligatorias y otras opcionales, y normalmente contiene referencias a otros textos legales que se puede utilizar para crear una red de hipertexto.

Teniendo en cuenta, como se ha señalado, el carácter oficial que muchos de los documentos legislativos representan y que constituyen la fuente obligatoria de las conductas jurídicas, a la vez que configuran el patrimonio legislativo de una nación, no todos los estándares XML son adecuados para representar los documentos legislativos, pues su fragmentación y calificación puede hacer perder la integridad del documento original.

De este modo, surgió el estándar XML Legislativo (Legal XML), que está orientado a conservar íntegro el valor del documento legal y a explotar toda la potencialidad de XML para mejorar el flujo legislativo.

Efectivamente, tal como lo señala García Marco (2009), tempranamente el mundo jurídico reconoció la importancia de esta herramienta, y de este modo existen casi desde el lanzamiento del estándar dos organismos especializados en el estudio del 
XML Legislativo. En Estados Unidos, en 1998, surge LegalXML (integrado desde 2002 en OASIS, Organization for the Advancement of Structured Information Standards) y en Europa, en 2001, LEXML, integrado por varias jurisdicciones.

Sin embargo, algunos de estos estándares sólo alcanzan objetivos y procesos parciales, mientras otros fueron creados para todos los documentos jurídicos de sistemas jurídicos determinados.

Palmirani y Vitali (2012: 25) hacen un recorrido histórico en la evolución del XML legislativo distinguiendo las siguientes generaciones:

- La primera generación del estándar de documento legal XML se orientó sobre todo a describir el texto legal y su estructura con un enfoque cercano a las entidades de base de datos (database entities) o el procesamiento tipográfico de paradigmas. Ejemplo de esta generación son EnAct, utilizado en Tasmania, Australia, Nueva Zelanda y Canadá, y FORMEX, utilizado en EUR-LEX.

- La segunda generación empleó una mayor atención en la modelización del documento y la descripción del texto, la estructura y los metadatos. Ejemplos son NormeinRete (NIR) en Italia y LexDania ${ }^{23}$ en Dinamarca. Sin embargo, el carácter descriptivo de los elementos no fue precedido por un análisis abstracto de las clases de datos y el resultado es una lista demasiado larga de etiquetas, una compleja inclusión de esquemas XML o DTD, con una frecuente superposición entre los metadatos y la definición de texto y unos instrumentos demasiado débiles para unir el texto con diferentes niveles.

- La tercera generación se basa en el patrón (pattern). El patrón define las propiedades de la clase y su gramática, el modelo del contenido, el comportamiento y el respeto a la jerarquía de otras clases, por lo que cualquier tag adicional pertenece a una clase abstracta ya existente y de esta manera se preserva la coherencia a través del tiempo. Se dedicó especial atención a dividir el texto, la estructura y los metadatos y se mira a la ontología como un principio fundamental para realizar un seguimiento en firme de cualquier nuevo nivel (layer) colocado en la parte superior del texto puro. Debido a que el patrón define unas reglas generales que ya no están sujetas a limitaciones reales en la acción de markup, la claridad del diseño favorece su carácter prescriptivo. Akoma Ntoso, creado en 2004, financiado por Naciones Unidas en el ámbito del Plan de Acción de Naciones Unidas África i-Parliaments para apoyar el acceso abierto en los parlamentos africanos, y Metalex son buenos ejemplos de esta visión.

- La cuarta generación utiliza el patrón (pattern) junto con una correstricción a

23. LexDania, sistema legal danés. Disponible en http://bit.ly/2jSMZt1. 
modo gramatical para resolver el problema mencionado de la falta de carácter preceptivo.

En varios países europeos se ha adoptado el XML Legislativo.

En el ámbito que nos ocupa, el modelo de servicio, un elemento esencial de este XML legislativo y la técnica aprobada oficialmente por varios países para garantizar la validez jurídica de los documentos legislativos, es la firma electrónica. A través de ella es posible asegurar la autenticación del autor, la integridad del documento firmado y el no repudio de la procedencia del mismo.

Por lo anterior, se verá cómo en la mayoría de los países la combinación de este estándar, junto a técnicas de firma electrónica y un estricto control del proceso de elaboración y publicación, garantiza la autenticidad e integridad del documento electrónico, y como consecuencia también la validez de la publicación oficial. En particular, el Instituto Europeo de Normas de Telecomunicaciones (ETSI) y otros organismos de estandarización recomiendan al respecto el uso de XAdES (firma electrónica avanzada XML), un formato de algoritmos criptográficos de sonido, para la gestión de sobres de firma digital avanzados. En la mayoría de estas plataformas que sustentan los servicios de información legal, el proceso de publicación electrónica oficial comienza desde un documento en formato XML que luego se transforma en una presentación al usuario final, sea para formato impreso como para presentación web.

Desde el punto de vista de la gestión, entonces, se puede asegurar que, en este ámbito, el gran desafío se traduce en equilibrar tres aspectos principales:

- preservar en la medida de lo posible la separación entre el contenido del documento legal tal como fue producido por el autor original, de los metadatos y atributos añadidos en el flujo de trabajo del procesamiento posterior;

- preservar el carácter descriptivo de la semántica del formato del documento; y

- mantener la validez jurídica de la manifestación del documento (manifestación expresada eventualmente en un diseño gráfico en particular o en una firma de la autoridad emitente).

\section{Metadatos}

El segundo gran pilar de la web semántica son los metadatos, que según la definición más difundida son «datos sobre datos». Por su parte, Sheldon los define en su Linktionary ${ }^{24}$ como «informaciones sobre datos», Steinacker, Ghavam y Steinmetz (2001) como «informaciones sobre informaciones», y Durrel (1985) como «datos estructurados y codificados que describen características de instancias conteniendo

24. «Metadata», Linktionary, 2001. Disponible en http://bit.ly/2jV91Lu. 
informaciones para ayudar a identificar, descubrir, valorar y administrar las instancias descritas». Para Palmirani y Vitali (2012), constituyen cualquier consideración o comentario adicional que puede expresarse sobre el contenido y sobre el documento. Para estos autores resulta determinante en su conceptualización que la información no haya sido proporcionada por el autor en el documento.

Los metadatos son generados por intervención humana o a través de procesos automáticos. Los profesionales de la documentación han usado los metadatos durante cientos de años. De hecho, el catálogo de una biblioteca, que ayuda a estos profesionales a gestionar sus libros y revistas y a los usuarios a la recuperación de los mismos, es un ejemplo popular y no muy complejo de uso de metadatos.

En el ámbito de la web semántica, la marca descriptiva en XML es, en sí misma, una forma de metadatos; sin embargo, la semántica que define es solo parcial, y de ahí que el $\mathrm{W}_{3} \mathrm{C}$ desarrolló una de las primeras aplicaciones surgidas del metalenguaje XML, el RDF (resource description framework), considerado un metamodelo de metadatos que permite codificar distintos esquemas de metadatos y además crear otros vocabularios específicos a través del lenguaje para la descripción RDF o RDFS (RDF Schema).

En el ámbito legislativo, Müller (2002) propone la creación de un diccionario legal RDF en Europa, iniciativa en la que se pretendía aplicar el modelo de metadatos Dublin Core. Por su parte, en Estados Unidos se propone un diccionario similar con todos los términos legales que puedan aparecer en la DTD XML Legal. En la actualidad, el sistema legal danés LexDania, uno de los pocos en el mundo en que el Gobierno y el Parlamento trabajan en una base de datos común durante todo el proceso de producción de la ley, implementa metadatos expresados en RDF. Asimismo, cabe destacar la creación del grupo de trabajo denominado «Common use of XML for the production and distribution of official gazettes», creado en el contexto del European Forum of Official Gazettes con la intención de que la cooperación entre los editores de boletines oficiales europeos conduzca a la creación de un vocabulario que simplifique el desarrollo y uso de los modelos XML específicos de los documentos legislativos. El grupo ha propuesto un vocabulario común de metadatos, dado que ninguno de los modelos preexistentes se adaptaba a la descripción de documentos jurídicos. La implementación del modelo, que no excluye la posibilidad de incorporar metadatos específicos, entre otras indudables ventajas supone un apoyo decidido al empleo de estructuras XML normalizadas para la búsqueda e intercambio de metadatos en el entorno de la información legal.

\section{Ontologías}

La tercera herramienta fundamental de la Web Semántica la constituyen las ontologías. Este término, que tiene su origen en la filosofía, se ha aplicado en muchas mane- 
ras diferentes. Según Garshol (2004), el significado básico en las ciencias informáticas, donde nació y se desarrolló dentro de la inteligencia artificial, refiere a un modelo para describir el mundo que consiste en un conjunto de recursos, propiedades y tipos de relación. Su objetivo era desarrollar formalismos para describir mediante el lenguaje de la lógica el sistema conceptual de un determinado dominio de la actividad humana de tal manera que dicha descripción pueda soportar mecanismos de inferencia automatizados.

Este esfuerzo se incorporó al proyecto de web semántica del $\mathrm{W}_{3} \mathrm{C}$ y se ha concretado en estándares sólidos como OWL (web ontology language). Como señala John Davies, citado por Benjamins y otros (2008: 78), proporcionan una capa de acceso uniforme a fuentes de datos heterogéneas, lo que permite vincular múltiples fuentes de información estructuradas, semiestructuradas y no estructuradas utilizando un vocabulario coherente. Para este autor, el mayor potencial de las ontologías reside en su apoyo a la navegación y recuperación conceptual que ya se revisó, pues conectar ontologías entre sí es relativamente fácil.

En el ámbito jurídico, este tipo de conceptualizaciones ocupan ya un espacio muy relevante, así por ejemplo EuroVoc, ${ }^{25}$ en la Unión Europea, utiliza una gestión de tesauros basada en ontologías y tecnologías de web semántica acordes con las recomendaciones del $\mathrm{W}_{3} \mathrm{C}$. En efecto, en los estudios y desarrollos de la web semántica respecto de las ontologías, los campos de experimentación se multiplican y el campo de derecho es uno de los que ha recibido un interés especial, tanto por su carácter transversal a las diferentes realidades sociales, políticas y económicas como por las propias características de la documentación jurídica que, como adelantáramos, combina tanto lenguaje natural como técnico, así como por la existencia de distintos modelos de sistemas jurídicos que ofrecen términos semánticamente diversos. Un ejemplo característico lo ofrece el vocablo jurisprudencia, cuyo contenido y alcance difiere en el sistema continental y anglosajón. También son ejemplos recurrentes la tipología de normas jurídicas, las denominaciones de las clases de vinculaciones que pueden existir entre las normas, y el nombre que toman las distintas estructuras al interior de la norma (libro, título, capítulo, sección o párrafo, por ejemplo).

Una gran potencialidad de las ontologías es, precisamente, ofrecer vistas personalizadas y agregadas de esos recursos a partir de la descripción sistemática de los conceptos de recuperación y de la interconexión entre ontologías diversas, pues toda ontología se configura en respuesta a necesidades específicas, que varían según grupos de usuarios y contextos. Se trata de agrupar diferentes clasificaciones en una misma ontología, de manera que la información se busque y se muestre mediante las categorías y la terminología más naturales para el usuario.

Es importante señalar, sin embargo, que las ontologías requieren, recíprocamente,

25. EuroVoc, Tesauro Multilingüe de la Unión Europea. Disponible en http://eurovoc.europa.eu. 
la descripción de los recursos y servicios. El problema es la cantidad de personal, tanto para el análisis como para la coordinación y supervisión, que resulta necesaria para llevarla a cabo. Por ello, al igual que en otros campos de aplicación, una de las líneas en desarrollo que debe ser atendida es la asignación automática o asistida de metadatos, a partir de la interconexión propuesta por las ontologías aplicadas.

\section{Usos y ventajas de la utilización de la web semántica legislativa}

En términos generales se reconocen grandes ventajas a la web semántica legislativa, entre las cuales se destaca que favorece el intercambio de documentos entre los órganos legislativos, permite búsquedas extensas con resultados más precisos, posibilita la vinculación entre documentos e incluso entre secciones del mismo, habilita el acceso a la documentación a través de múltiples canales, homogeniza los formatos de los documentos y en este sentido puede apoyar la técnica legislativa y garantiza la conservación a largo plazo de los documentos. Siguiendo los trabajos que sobre la materia han desarrollado tanto García Marco (2009), como Palminari y Vitali (2012), a continuación se examinan estas ventajas.

Las primeras tienen que ver con la utilización del lenguaje XML y son: valor agregado del marcaje colaborativo; consolidación automatizada de los textos legales; reutilización de contenidos y distribución multicanal; navegación híper e intertextual mediante tablas de contenido y enlace; conservación y preservación a largo plazo; así como el apoyo a la redacción normativa. Las demás ventajas, en tanto, se relacionan con el uso de RDF y OWL y refieren a: la navegación y recuperación conceptual; acceso multilingüístico; análisis de datos y generación de reportes; así como el estudio de coherencia y consistencia normativa. Además de las anteriores, se destaca como ventaja la interoperabilidad de los servicios que sin duda constituye un elemento fundamental hoy en día para la gestión de información. Pasamos a revisar cada una en particular.

\section{Valor agregado del marcaje colaborativo}

Sin duda, uno de los elementos fundamentales de los estándares XML es la anotación o marcaje de los textos legales, lo que constituye la base de todas las tecnologías semánticas.

Gracias a las tecnologías desarrolladas, este proceso puede ser convertido fácilmente en una actividad colaborativa. Durante su realización es posible agregar todas las supervisiones y controles necesarios identificando autores (con sus roles y permisos bien definidos) y fechando los cambios adecuadamente para obtener la completa trazabilidad del documento. Como es comprensible, estas marcas, con los muy variados contenidos a incorporar, pueden llegar a ser de interés de agentes muy diferentes: 
legisladores, jueces, académicos, documentalistas, periodistas, ciudadanos, editores jurídicos interesados, entre otros sectores, lo que significa que pueden dar lugar a un enriquecimiento del texto legal realmente valioso. Un objetivo deseable sería ir clasificando los actores y los tipos de anotaciones de cara a la construcción de estándares en RDF Schemas que, posteriormente, pudieran ligarse a ontologías.

\section{Consolidación automatizada de los textos legales}

La web semántica —en especial el marcado XML_ puede ser utilizada para crear de modo semiautomático las versiones de los textos legales generadas a partir de las modificaciones, en cada momento temporal, lo que forma el cuadro de versiones de los textos consolidados o actualizados. Así, pues, no estará disponible únicamente la última versión, sino toda la cadena de las versiones producidas en el tiempo. Estos textos, debidamente identificados, pueden ser almacenados, recuperados, presentados posteriormente en la línea de tiempo e incluso comparados por los usuarios. Al mismo tiempo, es posible utilizar esta información ex ante para generar simulaciones del sistema normativo ante la introducción de modificaciones o nuevas normas. Lo anterior permite verificar el impacto de la regulación y también la corrección de muchas referencias normativas, con el fin de incrementar la calidad legislativa.

\section{Reutilización de contenidos y distribución multicanal}

Como se ha revisado anteriormente, un elemento esencial hoy en día en los servicios de información legislativa lo constituye la apertura de los datos, que implica la posibilidad de uso, reutilización y redistribución de la información a la que en estos servicios se accede por cualquier ciudadano y también por las empresas que ofrecen servicios con valor agregado sobre la información y documentación legislativa. Es un hecho cierto que estos usuarios utilizan la World Wide Web de forma generalizada para sus tareas de búsqueda, recuperación, difusión y distribución de la información.

En el caso de las empresas editoras y distribuidoras de información legal, una vez formalizados los sistemas de representación para el almacenamiento y la difusión, a través de las herramientas de la web semántica el proceso de selección y presentación puede resultar enormemente beneficiado por la gestión automatizada de los procesos y flujos de trabajo involucrados e incluso incorporar, al final de cada flujo, una gestión automatizada para una oferta editorial múltiple y variada. Para ellas, la web semántica permite, sobre todo, tener la información estructurada y organizada en un repositorio para su reutilización en su oferta de productos. Posteriormente lo podrán utilizar en guías legales, manuales, compilaciones, boletines de difusión selectiva, apps, bases de datos u otros soportes, generados especialmente para ajustarse a las necesidades de sus clientes focalizados (mercado objetivo). 
En algunas experiencias europeas esta información es fuente reutilizable de formas de publicación más especializada. Los textos legales son de este modo enriquecidos, por ejemplo, por comentarios autorizados o dictámenes jurídicos, lo que lleva a la creación de nuevos mercados basados en la reutilización de los datos ya procesados. Lo anterior ocurre, por ejemplo, en el caso del portal gubernamental francés Legifrance, ${ }^{26} \mathrm{el}$ cual ha estipulado una serie de convenios especiales con los editores del sector jurídico especializado para proporcionarles todos los XML de las normas marcadas.

\section{Navegación híper e intertextual}

Puesto que las referencias dentro del documento (intradocumental o intertextual) y entre documentos (interdocumental o hiperdocumental) constituyen un aspecto fundamental de la información legislativa, y en general de la jurídica, el hiper e intertexto se ha convertido en una herramienta imprescindible de estos servicios de información legislativa, pues incorpora agilidad al manejo de las referencias y de esta forma significa gran ahorro de tiempo para los usuarios.

Las referencias documentales en los textos legislativos se pueden clasificar en varios tipos. En primer lugar están las referencias intra o interdocumentales, que obedecen a la estructura jerárquica vertical del texto en función de las características del tipo de documento concreto, y que permiten navegarlo mediante tablas de contenido y sumarios. Éstas en general son fáciles de extraer automáticamente mediante las técnicas de marcado. En segundo lugar tenemos las referencias interdocumentales o hipertextuales, que conectan los diferentes documentos legislativos entre sí, para construir el enorme entramado del sistema jurídico. La referencia hipertextual tiene un carácter más amplio, al permitir la conexión de los textos legislativos con todos los documentos que los aplican, desarrollan, explican, interpretan, critican o valoran.

La extracción automática, así como la precisión y categorización de estos enlaces constituye una de las líneas de investigación más prometedoras de la web semántica legislativa y, a nuestro juicio, un aspecto clave para la mejora de la calidad de la legislación, pues la reunión del acervo jurídico puede transformarse en un insumo básico para una evaluación de los preceptos normativos que apoye las actividades de simplificación legislativa.

\section{Conservación y preservación a largo plazo}

Una de las implicaciones más importantes de los estándares de la web semántica resulta de uno de sus objetivos manifiestos: la estabilidad. Al definir formatos estables para codificar caracteres, imágenes, estructuras documentales, metadatos y relacio-

26. Legifrance, sistema de información jurídica de Francia. Disponible en http://www.legifrance.gouv.fr/. 
nes conceptuales, la web semántica sienta las bases para la preservación a largo plazo de la información.

Efectivamente, los documentos jurídicos desmaterializados, modelados y representados en XML preservan el valor jurídico en el tiempo y separan claramente el contenido auténtico, aquél autorizado junto con la formalización de su aprobación, de las muchas reelaboraciones que suceden durante el ciclo informativo. Para este efecto, como se ha visto, es necesario incluir la firma digital sobre el documento y congelar así el documento auténtico, aunque sea digital, para representarlo en el futuro sin la intermediación de aplicaciones.

Hay, sin embargo, mucho trabajo por hacer. Especialmente, es necesario desarrollar estándares para almacenar los documentos originales y «máster» de forma independiente de las marcas y anotaciones, sin perjuicio de su accesibilidad. Con el tiempo, uno de los efectos más importantes de la web semántica debería ser la radical reducción en la redundancia de la información, de manera que se dirija inequívocamente a los documentos originales y sus copias autorizadas y que en el estatus de cada documento legal de la internet quede clara su autenticidad y autoría.

\section{Apoyo a la redacción normativa}

Los documentos producidos con las herramientas de la web semántica son estructurables y, por tanto, pueden colaborar en la elaboración del texto legislativo en lo que refiere a su estructura lógica. Lo anterior, por ejemplo, se llevaría a cabo simplificando la construcción de párrafos y numeraciones dentro de los artículos, advirtiendo sobre textos repetidos u omisiones en la estructura, facilitando la aplicación de enmiendas, estandarizando los textos de encabezamiento y promulgación, recomendando la utilización de citas y referencias normativas y muchos otros elementos que sin duda contribuyen al perfeccionamiento del texto legal.

\section{Navegación y recuperación conceptual}

Una ventaja indiscutida de la web semántica es la navegación y recuperación de la información a nivel conceptual. La utilización de RDF y de los esquemas de descripción de recursos como Dublin Core ofrece la capa intermedia para conectar los documentos estructurados con las ontologías. Ello permite luego organizar la información en respuesta a preguntas cada vez más complejas y sofisticadas, a través de menús navegables y mapas conceptuales, que es la forma en que la internet se hace inteligible para los usuarios.

Una de las aplicaciones más útiles de las ontologías es precisamente la de facilitar la anotación semántica: identificación de lugares, organizaciones, personas, documentos, procesos y objetos mencionados en los documentos legales y en los otros 
textos relacionados con ellos. Así, por ejemplo, un sistema basado en ontologías puede asociar fácilmente varias denominaciones de la misma entidad, como por ejemplo Municipalidad de Santiago, Municipio de Santiago, Alcaldía de Santiago, etcétera; o también puede ampliar la búsqueda a partir de las relaciones contenidas en la ontología: por ejemplo, desglosar las comunas en una búsqueda sobre ordenanzas locales. $\mathrm{Al}$ respecto, se sugiere ver la visualización mostrada por el sistema Ley Chile de la Biblioteca del Congreso Nacional, que permite obtener las ordenanzas municipales por cada comuna recorriendo el mapa de Chile.

\section{Acceso multilingüístico}

La legislación tiene un carácter territorial y por tanto se encuentra ligada al ámbito de la jurisdicción en la que se produce. Por esta razón debe ser expresada en las lenguas oficiales de ese territorio. No obstante, la consabida globalización, la demanda de validación y respeto de las lenguas minoritarias dentro del Estado, y la consolidación de bloques regionales formados por Estados con idiomas distintos (Unión Europea, Mercosur, Asia Pacífico, etcétera), exigen la consideración de servicios de información legislativa formulados en diferentes lenguas. Las tecnologías de la web semántica, como RDF u OWL, constituyen un aporte a la interconexión de terminologías utilizadas en los textos legislativos en los diferentes idiomas en el ámbito de la internet.

\section{Análisis de datos y reportes}

Un desarrollo esperado de la web semántica es la obtención de datos sobre los procesos legislativos, su valoración, sus efectos y su impacto, lo que sin duda constituye un aporte incalculable para dar respuesta a las demandas de transparencia legislativa y de mejora de la calidad de la legislación.

Las ontologías legales pueden servir en este campo como instrumentos para recuperar información etiquetada, que después sería procesada mediante técnicas estadísticas por programas semánticos (robots) para facilitar los procesos de evaluación, opinión y decisión política, facilitando y proporcionando valor - por ejemplo- al trabajo de los observatorios legislativos ciudadanos, académicos o de medios. Al respecto, García Marco considera que

uno de los campos de aplicación que se vislumbra más interesante es la conexión con los sistemas de estadística social y otro, que obviamente interesa enormemente a los políticos, es el análisis del impacto mediático de la actividad legislativa. Por una parte, los políticos son especialmente sensibles a los problemas que aparecen en los medios, los cuales, en muchas ocasiones, condicionan el noventa por ciento de sus iniciativas políticas. Por otra, los medios dedican una cobertura importante en noticias y opinión a la actividad legislativa (García Marco, 2009: 76). 
En nuestra opinión, esta funcionalidad podría dar respuesta a la demanda de legitimidad de la actividad legislativa.

\section{Revisión de la coherencia del sistema legal}

Este ámbito tan necesario tiene un desarrollo incipiente en algunos países a la fecha. El mismo constituye un desarrollo ambicioso de la web semántica y de enormes repercusiones para la disciplina de técnica legislativa, especialmente para las tareas de simplificación legislativa, tales como la derogación, codificación, refundición y consolidación normativa.

En efecto, lograr detectar antinomias, incoherencias e inconsistencias, de forma automática entre los textos legales, contribuiría de manera significativa a las tareas de elaboración y depuración normativa y por consiguiente a la consecución de las garantías de certeza y seguridad jurídica. Para ello, se ha trabajado en utilizar un marcado muy detallado y específico de la legislación con el objeto de procesar la coherencia de los textos legales y su conformidad con otras normas promulgadas anteriormente.

Aquí se trata del desarrollo de sistemas automáticos para asistir a los legisladores y a los órganos que están obligados a informar o supervisar las nuevas leyes y normas, teniendo en cuenta que se encuentran legislando en un entorno de alta contaminación normativa. Este tipo de aplicaciones enlaza directamente con los sistemas expertos y con los programas de inteligencia artificial, por lo que su diseño e implementación constituye un desafío en materia de trabajo multidisciplinario, que al mismo tiempo demanda un alto grado de desarrollo de nuevas competencias entre los profesionales y técnicos que participan en estos procesos.

\section{Interoperabilidad}

De acuerdo con el artículo 2 letra a de la Decisión 2009/922/CE, del Parlamento y Consejo Europeo, la interoperabilidad es:

La capacidad de que organizaciones diversas y dispares interactúen con vistas a alcanzar objetivos comunes que sean mutuamente beneficiosos y que hayan sido acordados previa y conjuntamente, recurriendo a la puesta en común de información y conocimientos entre las organizaciones, a través de los procesos empresariales a los que apoyan, mediante el intercambio de datos entre los sistemas de TIC respectivos.

Así entendido, la interoperabilidad es piedra angular de muchos de los servicios del gobierno de la información en nuestra sociedad red, pues a través de ella se permite el intercambio continuo y fluido de documentación y servicios entre las distintas agencias, públicas y privadas, nacionales e internacionales, lo que evita duplicaciones o repeticiones de trabajo. A nuestro juicio, es también un elemento esencial en 
la configuración de un servicio de información legislativa que asegure el derecho a esta información.

En la práctica, se ha establecido que para lograr una arquitectura de interoperabilidad adecuada se requiere la adhesión a estándares comunes y considerar además una arquitectura multicapa, que resuelva y especifique cada uno de los siguientes elementos en detalle:

- Ventanilla única o punto de contacto estandarizado, consistente y eficiente, que le permita al ciudadano acceder a los servicios de un determinado servicio por múltiples canales. Hoy en día, en varios países europeos se está pensando que estos puntos de contacto se transforman en servicios compartidos (shared services) entre servicios públicos.

- Interoperabilidad organizacional, es decir, coordinación y alineamiento entre los procesos de negocios y la información de diferentes instituciones.

- Interoperabilidad semántica, para asegurar el entendimiento en el significado de cada componente del proceso de intercambio de información y por tanto la existencia de estructuras estándares.

- Interoperabilidad técnica, es decir, la definición de los componentes tecnológicos necesarios para lograr el modelo de interoperabilidad adoptado.

Más específicamente, los metadatos y las estructuras para representar la documentación legal electrónica, base - como se ha señalado- de la web semántica legislativa, son el primer paso para soportar esta interoperabilidad entre los entes públicos que soportan servicios que utilizan como cimiento esta información. Como se sabe, en el proceso legislativo intervienen varios actores y sin duda la interoperabilidad es un valor importante para que todo el flujo de trabajo (workflow) pueda proceder rápidamente, sin pérdidas de tiempo, con ahorro de esfuerzo. Un ejemplo de esto ocurre por ejemplo con la elaboración de los reglamentos de la ley que pueden utilizar los textos y referencias normativas ya contenidas en el texto legal.

Además de lo anterior, la interoperabilidad facilita el análisis comparativo de la legislación extranjera, al permitir conectar las fuentes legales de varios países. Tal es el caso, por ejemplo, de desarrollos más avanzados en servicios legislativos gubernamentales en línea, como ocurre con el modelo de LexDania, en Dinamarca. También se destaca Legislation UK Gov de Reino Unido, ${ }^{27}$ que distribuye esta información a redes mundiales, cuestión que también se desarrolla en el sistema Ley Chile de la Biblioteca del Congreso Nacional de Chile.

27. Legislation United Kingdom, sistema de información legal de Reino Unido. Disponible en http:// www.legislation.gov.uk/. 


\section{Conclusiones}

El derecho a la información legislativa es una exigencia que se impone en un ordenamiento jurídico democrático, ya que en términos de derechos individuales se trata de la información que rige nuestra conducta en sociedad. Del mismo modo, podemos afirmar que esta información constituye el patrimonio legislativo y forma parte del capital social de la nación.

Los servicios, métodos e instrumentos tradicionales de gestión de información legislativa requieren ser redefinidos, pues no cumplen con las exigencias impuestas por la sociedad red. Uno de los principales cambios lo constituye la publicación electrónica y en este sentido son múltiples los países que han reconocido o dispuesto de mecanismos oficiales de publicación de las leyes en soportes electrónicos, de acceso libre y gratuito. Sin embargo, como se observa también, hoy día el contenido manda; por tanto, el principal desafío de la publicación normativa electrónica es garantizar el acceso y preservación de los contenidos legislativos oficiales, de forma independiente a los formatos y las soluciones técnicas.

El concepto de «diario» es legado de la era de impresión y resulta desactualizado en este nuevo escenario en que la publicación electrónica es el estándar adoptado. Los contenidos legales se pueden publicar hoy en línea sobre una base de continuidad, cada minuto o cada hora de ser necesario. Así serán también requeridos en consulta por los usuarios. Bajo este contexto, uno de los elementos que en la actualidad resulta crucial es la implementación de plataformas electrónicas de consulta y procesamiento de esta información que aseguren la autenticidad, integridad y preservación del texto publicado, elementos sin los cuales no es posible proveer certeza legal a los ciudadanos.

La redefinición de la gestión de información legislativa, en los términos expresados, requiere, entre otros elementos, de servicios oficiales de información legislativa, bajo los estándares de apertura, autenticidad, seguridad de la información y gestión de calidad, y basados en el modelo de web semántica imperante.

Un servicio oficial de información legislativa abierto es aquél que otorga acceso a información auténtica bajo estándares que permiten que los datos además puedan ser usados, reusados y redistribuidos por cualquiera que acceda a ellos.

Los principales estándares de apertura reconocidos universalmente para estos servicios son:

- Gratuidad, pues se debe entender que esta información tiene carácter público y genera además un alto valor público. De esta manera debe ser provista por el Estado, quien está llamado a garantizar que el ciudadano conozca las normas legales.

- Disponibilidad, que implica que la totalidad del proceso de publicación debe 
estar implementado de tal modo de garantizar un alto nivel de disponibilidad de los recursos humanos y de las plataformas técnicas de servicios de consulta y de producción, las veinticuatro horas del día, de los siete días de la semana.

- Licenciamiento libre, lo que significa que no esté sujeta a ningún tipo de copyright, patente u otro tipo de derecho, o dicho de otro modo, que las condiciones legales bajo las cuales está disponible esta información permitan su uso, redistribución, modificación, compilación o propagación ampliamente, sin limitación alguna y bajo cualquier propósito.

- Reserva excepcional, pues debe permitir la confidencialidad y resguardo de la información en aquellos casos definidos en la ley para la protección esencialmente de los derechos fundamentales de las personas o la seguridad nacional.

Un servicio de información legislativa oficial exige que, atendida la relevancia de los contenidos almacenados, se garantice a los usuarios la autenticidad, validez, integridad y preservación de los mismos.

El estándar de seguridad de la información exige adoptar todas las medidas técnicas y organizativas que se encuentren al alcance para garantizar una conservación y preservación de la información exenta de riesgos de adulteración, pérdida, tratamiento o uso no autorizado. Dada las características e importancia de la información asegurada, con estas medidas se protege su disponibilidad, integridad, autenticidad y preservación.

La gestión de calidad de sus procesos permite a los gestores del sistema monitorear la eficiencia y eficacia del mismo, su trazabilidad y a partir de ello promover su evaluación e instalación de procesos de mejora continua.

La web semántica legislativa aparece como un modelo de plataforma óptimo para la representación, organización y distribución de contenidos jurídicos bajo los estándares señalados, y constituye una respuesta eficaz a los requerimientos originados por el fenómeno de contaminación legislativa y a la demanda de mejor y más fácil acceso a la legislación, no sólo de los especialistas sino de los propios ciudadanos obligados por las normas jurídicas que integran el ordenamiento.

El modelo de web semántica legislativa, basado en las tecnologías de documento estructurado (XML), metadatos (RDF) y ontologías (OWL) presenta las siguientes ventajas: valor agregado del marcaje colaborativo; consolidación automatizada de los textos legales; reutilización y distribución multicanal; navegación hiper e intertextual; conservación y preservación de la información a largo plazo; apoyo a la redacción normativa; navegación y recuperación conceptual; abordaje de la barrera lingüística; obtención de datos y generación de reportes, y revisión de la coherencia y consistencia normativa. 
Además de las anteriores, se destaca como ventaja la interoperabilidad de los servicios que permiten el intercambio fluido de documentación y servicios entre las distintas agencias públicas y privadas, nacionales e internacionales, lo que sin duda constituye un elemento fundamental para la gestión de la información legislativa en un mundo globalizado.

La revisión, para el levantamiento de estos estándares de gestión desde los sistemas europeos más avanzados, permite concluir que es necesario un cambio relevante de la forma de disponibilizar esta información a nivel nacional y regional.

\section{Referencias}

BARITÉ, Mario y María José López-Huertas (2004). «Los sitios web de legislación en el Mercosur: Un análisis comparativo». Ciência da Informação, 33 (2): 28-38. DOI: 10.1590/So100-19652004000200003.

Benjamins, Richard, John Davies, Ricardo Baeza-Yates, Peter Mika, Hugo Zaragoza, Mark Greaves, José Gómez-Pérez, Jesús Contreras, John Dominguez, John y Dieter Fensel (2008). «Near-term prospects for semantic technologies». IEEE Intelligent Systems, 23 (1): 76-88. DOI: 10.1109/MIS.2008.10.

Biglino Campos, Paloma (1993). La publicación de la ley. Madrid: Tecnos.

Castells, Manuel (2001). La era de la información: Economía, sociedad y cultura. Volumen 1: La sociedad red. 2. ${ }^{a}$ ed. Madrid: Alianza.

Codina, Luis y Cristófol Rovira (2006). «La web semántica». En Jesús Tramullas Saz (coordinador), Tendencias en documentación digital (pp. 9-54). Guijón: Trea.

Comisión EuRopea (1998). Libro verde sobre la información del sector público en la sociedad de la información: Un recurso clave para Europa. Luxemburgo.

Cotino, Lorenzo (2014). «El conflicto entre las libertades de expresión e información en internet y el derecho a la protección de datos. El derecho al olvido y sus retos». En Ignacio Bel y Loreto Correidora (directores), Derecho de la información. El ejercicio del derecho a la información y su jurisprudencia (pp. 387-430). Madrid: Centro de Estudios Políticos y Constitucionales.

Dalgleish, Andrew y Robert Hall (2000). «Uses and perceptions of the World Wide Web in an information-seeking environment». Journal of Librarianship and Information Science, 32 (3): 104-116. DOI: 10.1177/096100060003200302.

Díez Picazo, Luis (1999). Experiencias jurídicas y teoría del derecho. $3 .{ }^{a}$ ed. Barcelona: Ariel.

DurReL, William (1985). Data administration: A practical guide to data administration. Nueva York: McGraw-Hill.

Fernando Pablo, Marcos y Ricardo Rivero Ortega (2001). La publicidad de las sentencias en el orden contencioso-administrativo. . $^{\mathrm{a}}$ ed. Madrid: Civitas. 
Fornefeld, Martín, Gaby Boele-Keimer, Stefhan Recher y Michael Fanning (2009). «Assessment of the re-use of public sector information (PSI) in the geographical information, meteorological information and legal information sectors». Estudio elaborado por MICUS Management Consulting para la Comisión Europea. Disponible en http://bit.ly/2kxvxcL.

García Marco, Francisco Javier (2009). «Perspectivas sobre el uso de la web semántica en el tratamiento de información y documentación legislativa». Representación y Organización del Conocimiento, 15 (1): 59-85. Disponible en http://bit. ly/2kz6wOm.

Garshol, Lars Marius (2004). «Metadata? Thesauri? Taxonomies? Topic maps? Making sense of it all». Journal of Information Science, 30 (4): 378-391 DOI: $10.1177 / 0165551504045856$.

Menéndez MenÉndez, Aurelio (2004). La proliferación legislativa: Un desafío para el Estado de derecho. Madrid: Civitas.

MoORE, Mark (1998). Gestión estratégica y creación de valor en el sector público. Barcelona: Paidós.

MüLLER, Murk (2002). «Legal RDF dictionary». Presentación realizada en la conferencia XML Europe 2002. Disponible en http://bit.ly/2kxB4jx.

NITRD, Networking and Information Technology Research and Development Program of USA (2009). «Harnessing the power of digital data for science and society». Informe de grupo de trabajo. Disponible en http://bit.ly/2kx8mQ5.

Newbery, David, Lionel Bently y Rufus Pollok (2008). «Models of public sector information provision via trading funds». Disponible en http://bit.ly/2kvAaEk.

Palmirani, Mónica y Fabio Vitali (2012). «XML legislativo: Principios e instrumentos técnicos». Documento de debate, Banco Interamericano de Desarrollo. Disponible en http://bit.ly/2kxIVxL.

SAARENPä̈̈, Ahti (2005). «Gestión y administración pública electrónica: Aspectos de la planificación jurídica en una sociedad de red». Revista Chilena de Derecho Informático, 7: 15-25. Disponible en http://bit.ly/2kxxFkT.

-. (2012). «Legal well-being and legal informatics: The view from the University of Lapland». Texto proporcionado por el autor. Helsinki.

Steinaker, Achim, Amir Ghavam y Ralf Steinmetz (2001). «Metadata standards for web-based resources». IEEE MultiMedia, 8 (1): 70-76. DOI: 10.1109/93.923956.

Torres Lana, José Ángel (2005). «La publicación on-line de la norma jurídica». Revista de Aranzadi de Derecho y Nuevas Tecnologías, 8: 17-37.

Uhlir, Paul (2004). Orientaciones sobre políticas para la elaboración y promoción de información oficial de dominio público. París: Unesco. 


\section{Sobre la autora}

Patricia Reyes Olmedo es abogada. Doctora en Derecho por la Universidad Complutense de Madrid, España. Magíster en Gestión de Organizaciones por la Universidad de Valparaíso, Chile y licenciada en Ciencias Jurídicas y Sociales por la Universidad de Chile. Actualmente se desempeña como docente de Derecho y Tecnologías de la Escuela de Derecho de la Universidad de Valparaíso. Su correo electrónico es patricia.reyes@uv.cl. 


\title{
REVISTA CHILENA DE DERECHO Y TECNOLOGÍA
}

La Revista de Chilena de Derecho y Tecnología es una publicación académica semestral del Centro de Estudios en Derecho Informático de la Facultad de Derecho de la Universidad de Chile, que tiene por objeto difundir en la comunidad jurídica los elementos necesarios para analizar y comprender los alcances y efectos que el desarrollo tecnológico y cultural han producido en la sociedad, especialmente su impacto en la ciencia jurídica.

\author{
EDITOR GENERAL \\ Daniel Álvarez Valenzuela \\ (dalvarez@derecho.uchile.cl) \\ SITIO WEB \\ rchdt.uchile.cl \\ CORREO ELECTRÓNICO \\ rchdt@derecho.uchile.cl \\ LICENCIA DE ESTE ARTÍ́CULO \\ Creative Commons Atribución Compartir Igual 4.0 Internacional
}

\begin{abstract}
y
La edición de textos, el diseño editorial

y la conversión a formatos electrónicos de este artículo

estuvieron a cargo de Tipográfica

(www.tipografica.cl).
\end{abstract}

